\title{
Impact of single nucleotide polymorphisms in the VEGFR2 gene on endothelial cell activation under non-uniform shear stress
}

\author{
NORA M. SCHACHER ${ }^{1}$, DORETTE RAAZ-SCHRAUDER ${ }^{1}$, FRANCESCA PASUTTO ${ }^{2}$, FLORIAN M. STUMPFE $^{3}$, \\ MIYUKI TAUCHI $^{1}$, BARBARA DIETEL ${ }^{1}$, STEPHAN ACHENBACH $^{1}$ and KATHARINA URSCHEL ${ }^{1}$ \\ ${ }^{1}$ Department of Medicine 2-Cardiology and Angiology, Erlangen University Hospital, \\ Friedrich-Alexander University Erlangen-Nürnberg, D-91054 Erlangen; ${ }^{2}$ Institute of Human Genetics, \\ Friedrich-Alexander University Erlangen-Nürnberg, D-91051 Erlangen; ${ }^{3}$ Department of Obstetrics \\ and Gynecology, Erlangen University Hospital, Comprehensive Cancer Center Erlangen-EMN, \\ Friedrich-Alexander University Erlangen-Nürnberg, D-91054 Erlangen, Germany
}

Received March 6, 2019; Accepted June 26, 2019

DOI: $10.3892 / \mathrm{ijmm} .2019 .4301$

\begin{abstract}
Single nucleotide polymorphisms (SNPs) in vascular endothelial growth factor receptor 2 (VEGFR2) are associated with coronary artery disease, hypertension and myocardial infarction. However, their association with atherosclerosis remains to be fully elucidated. The purpose of the present study was to determine whether SNPs are involved in atherogenesis, by analyzing their impact on human umbilical vein endothelial cells (HUVECs) under laminar and non-uniform shear stress in a well-established in vitro model that simulates shear stress-induced proatherogenic processes at vessel bifurcations. All experiments were performed using freshly isolated HUVECs. Three SNPs in the VEGFR2 gene (rs1870377 T>A, rs2071559 $\mathrm{A}>\mathrm{G}$ and $\mathrm{rs} 2305948 \mathrm{C}>\mathrm{T}$ ) were genotyped and the expression levels of VEGFR2 were semi-quantitatively determined using western blotting. Subsequently, the HUVECs were seeded in bifurcating flow-through cell culture slides and flow $(9.6 \mathrm{ml} / \mathrm{min}$ ) was applied for $19 \mathrm{~h}$, including tumor necrosis factor- $\alpha$ stimulation during the final $2 \mathrm{~h}$ of flow. The
\end{abstract}

Correspondence to: Dr Katharina Urschel, Department of Medicine 2-Cardiology and Angiology, Erlangen University Hospital, Friedrich-Alexander University Erlangen-Nürnberg, Schwabachanlage 12, D-91054 Erlangen, Germany

E-mail: katharina.urschel@uk-erlangen.de

Abbreviations: CAD, coronary artery disease; CVD, cardiovascular disease; EC, endothelial cell; HUVECs, human umbilical vein endothelial cells; HWE, Hardy-Weinberg equilibrium; MI, myocardial infarction; NF- $\kappa \mathrm{B}$, nuclear factor- $\kappa \mathrm{B}$; PECAM-1, platelet endothelial cell adhesion molecule-1; PI3K, phosphoinositide 3-kinase; SNP, single nucleotide polymorphism; TNF- $\alpha$, tumor necrosis factor- $\alpha$; VCAM-1, vascular cell adhesion molecule-1; VEGFR2, vascular endothelial growth factor 2

Key words: vascular endothelial growth factor receptor 2, single nucleotide polymorphism, endothelial dysfunction, atherosclerosis, shear stress, adhesion molecules protein expression levels of VCAM-1, E-selectin and VEGFR2 and the adhesion of THP-1 cells were analyzed in laminar and non-uniform shear stress regions. Data were analyzed for associations with the respective SNPs. The total expression of VEGFR2 was significantly lower under non-uniform shear stress than under laminar shear stress conditions, independent of the genotype. The expression of VEGFR2 between the different shear stress patterns was not significantly altered by the different SNPs. The expression levels of VCAM-1 and E-selectin were lower in the A/A genotype compared with those in other genotypes in rs1870377 T>A and rs2071559 $\mathrm{A}>\mathrm{G}$. In conclusion, the results suggested that SNPs within the $V E G F R 2$ gene have a significant impact on shear stress-related endothelial activation.

\section{Introduction}

The early stage of atherosclerotic plaque formation is characterized by endothelial dysfunction and inflammation. It has been shown that plaque development occurs at sites with disturbed blood flow, resulting in non-uniform shear stress acting on the endothelium (1). Hemodynamic forces at arterial bifurcations and curvatures have a marked impact on inflammatory gene expression in endothelial cells (ECs) $(2,3)$. In addition, several risk factors for cardiovascular disease (CVD), including hypertension, diabetes mellitus, hypercholesterolemia and smoking, contribute to injury and inflammation of the endothelium.

Non-uniform shear stress induces endothelial dysfunction characterized by the expression of inflammatory cytokines and chemokines, increased endothelial permeability and leukocyte recruitment, and elevated expression of adhesion molecules, including vascular cell adhesion molecule-1 (VCAM-1) and E-selectin (4,5). By contrast, laminar shear stress in straight vessel segments induces laminar cell alignment and a quiescent phenotype in ECs, which prevents EC activation, and thus has an atheroprotective effect (6).

For several years it has been known that ECs express receptors to sense the hemodynamic status. Accordingly, the endothelium acts as a dynamic interface between hemodynamic 
factors and the vascular wall. A mechanosensory complex on the EC surface is composed of platelet endothelial cell adhesion molecule 1 (PECAM-1), vascular endothelial cadherin (VE-cadherin) and vascular endothelial growth factor receptor 2 (VEGFR2) transducing the physical properties of flow into an equivalent intracellular signal (7).

VEGFR2 is one of the three VEGF receptors, and its activation affects vascular permeability in addition to the proliferation, migration, differentiation and survival of ECs $(8,9)$. Studies using VEGFR2-knockout mice have revealed that this receptor is indispensable for the development and formation of a blood vessel network, leading to fetal lethality in these mice $(9,10)$. The activation of VEGFR2 triggers the conformational activation of integrins followed by the stimulation of nuclear factor- $\kappa \mathrm{B}(\mathrm{NF}-\kappa \mathrm{B})(11)$, a transcription factor responsible not only for adaptation to flow but also for the de novo synthesis of adhesion molecules, including VCAM-1, E-selectin and ICAM-1. Therefore, the expression of VEGFR2 regulates endothelial activation by influencing the expression of adhesion molecules, leading to enhanced leukocyte adhesion that contributes to atherosclerotic plaque formation. Increased plasma levels of VEGF, which activates VEGFR2, are associated with the occurrence of atherosclerosis and coronary artery disease (CAD) $(12,13)$. In our previous study, it was shown that the knockdown of VEGFR2 in human umbilical vein endothelial cells (HUVECs) decreased the expression of adhesion molecules and consequently reduced monocyte adhesion in regions of non-uniform shear stress. This effect was mediated by inhibition of the translocation of $\mathrm{NF}-\kappa \mathrm{B}$ from the cytoplasm to the nucleus (14).

The heritability of CVD is estimated to be 50-60\% (15). In this context, single nucleotide polymorphisms (SNPs) have been a focus of interest for several years (16-19). Regarding VEGFR2, which consists of 1,356 amino acids, several hundreds of SNPs have been identified and are reported to be associated with the angiographic severity of atherosclerosis in patients with CAD (15). In particular, a study examining two independent populations showed that three SNPs in VEGFR2, rs2305948 C $>$ T, rs1870377 T >A and rs2071559 A $>$ G, are associated with an increased risk of CAD (20), most likely due to their role in blood vessel formation $(10,21)$. Associations have been reported between $\mathrm{rs} 2071559 \mathrm{~A}>\mathrm{G}$ and $\mathrm{CVD}$; the $\mathrm{G} / \mathrm{G}$ genotype is more frequent than other genotypes in patients with type 2 diabetes and myocardial infarction (MI) (22), although the $\mathrm{G}$ allele showed a protective effect against CVD by increasing high-density lipoprotein cholesterol in an Asian population (23). Therefore, evidence suggests that SNPs in the VEGF/VEGFR2 system may be involved in the development of atherosclerosis. Furthermore, SNPs in PECAM-1, another member of the above-mentioned mechanosensory complex, have been shown to be associated with MI (24), atherosclerosis (25), ischemic stroke (26) and monocyte adhesion to endothelial cells (27).

Although the sensitivity of VEGFR2 to shear stress is well described, no information exists on the impact of the SNPs in VEGFR2 on shear stress-induced endothelial dysfunction on a molecular basis.

In terms of the present study, it was hypothesized that SNPs in VEGFR2 alter the expression of genes that are associated with endothelial cell activation (i.e., VCAM-1 and E-selectin) under different shear stress conditions. To test this hypothesis, the molecular responses in ECs to laminar and non-uniform shear stress were analyzed using a well-characterized in vitro flow chamber model. This model mimics hemodynamic properties at vessel bifurcations comparable to physiological conditions (4).

\section{Materials and methods}

Determination of SNPs in HUVECs. Umbilical cords were collected at the Department of Obstetrics and Gynecology, Erlangen University Hospital, Comprehensive Cancer Center Erlangen-EMN, Friedrich-Alexander University Erlangen-Nürnberg (FAU; Erlangen, Germany), which was approved by the Ethics Committee of the Medical Department of the FAU (case no. 246-13B). The HUVECs were isolated from the freshly collected umbilical cords using standard techniques and cultured in endothelial cell growth medium (ECGM; Promo Cell) at $37^{\circ} \mathrm{C}$ in a humidified $7.5 \% \mathrm{CO}_{2}$ atmosphere. In all experiments, HUVECs at passages 1-2 were used.

Genomic DNA was extracted from 400,000-500,000 cells using the Promega ${ }^{\circledR}$ DNA-Isolation kit (Promega Corporation). All DNA samples were genotyped for the three selected SNPs in VEGFR2: rs1870377 $\mathrm{T}>\mathrm{A}$, rs2305948 $\mathrm{C}>\mathrm{T}$ and rs2071559 A $>$ G using TaqMan ${ }^{\circledR}$ SNP genotyping assays (Thermo Fisher Scientific, Inc.; assay nos. rs1870377: C-11895315_20; rs2305948: C-22271999-20, and rs2071559: C-15869271-10) with a reaction volume of $5 \mu \mathrm{l}$, on the QuantStudio ${ }^{\mathrm{TM}} 12 \mathrm{~K}$ Flex Real-Time PCR system following the manufacturer's protocol. The thermocycling steps were programmed as follows: Pre-read stage at $60^{\circ} \mathrm{C}$ for $30 \mathrm{sec}$; hold stage at $95^{\circ} \mathrm{C}$ for $20 \mathrm{sec}$; 50 cycles of PCR stages at $95^{\circ} \mathrm{C}$ for $3 \mathrm{sec}$ and at $60^{\circ} \mathrm{C}$ for $30 \mathrm{sec}$; post-read stage at $25^{\circ} \mathrm{C}$ for $30 \mathrm{sec}$. The primers are listed in Table I. TaqMan ${ }^{\circledR}$ Genotyper software (Thermo Fisher Scientific, Inc.) was used for accurate genotype calling and visualization of the data.

The linkage disequilibrium was analyzed to determine whether the frequencies of the three SNPs were related to each other by utilizing a web-based analysis tool (https://ldlink.nci. nih.gov/; LDpair, LDpop) $(28,29)$, using genome-wide association study (GWAS) data from the European population as the reference.

Expression levels of VEGFR2 in HUVECs. The basal expression level of VEGFR2 was determined semi-quantitatively. The HUVECs were harvested to extract total protein for a bicinchoninic acid protein assay (Thermo Fisher Scientific, Inc.) and 30-60 ng protein was used for western blotting. The samples were separated on $8 \%$ SDS-PAGE gels and transferred onto a PVDF membrane (Macherey-Nagel) via semi-dry blotting. The membranes were blocked with $5 \%$ skim milk (Bio-Rad Laboratories, Inc.) in Tris-buffered saline with $0.1 \%$ Tween (TBS-T) or 3\% bovine serum albumin (Sigma-Aldrich; Merck KGaA) and stained with either anti-VEGFR2 antibody (cat. no. sc-505, 1:500, Santa Cruz Biotechnology, Inc.) in 2.5\% skim milk, or anti-vinculin antibody (cat. no. sc-25336, 1:500, Santa Cruz Biotechnology, Inc.) in TBS-T at $4^{\circ} \mathrm{C}$ overnight. The secondary antibodies anti-rabbit (cat. no. RPN4301, 1:10,000) and anti-mouse (cat. no. NX931, 1:50,000) coupled to horseradish peroxidase (Amersham; GE Healthcare Life Sciences) were incubated for $2 \mathrm{~h}$ at room temperature. The signals were 
Table I. TaqMan assay probes for analysis of vascular endothelial growth factor receptor 2 SNPs.

\begin{tabular}{llll}
\hline NCBI RefSNP ID & \multicolumn{1}{c}{ SNP } & \multicolumn{1}{c}{ Mutation } & \multicolumn{1}{c}{ Context sequence } \\
\hline rs1870377 T>A & \multirow{2}{*}{ Exon 11 } & Q472H Glu Q (CAA)> & 5'-GGTATGGGTTTGTCACTGAGACAGC[A/T] \\
& & His H (CAT) & TGGCTATAAGAAAGAGATAACAGCG-3' \\
rs2305948 C $>\mathrm{T}$ & Exon 7 & I297VVal V (GTA)> & 5'-TACAATCCTTGGTCACTCCGGGTTA[C/T] \\
& & Ile I (ATA) & ACCATCTATAGTTAAGGTGCTCAAA-3' \\
rs2071559 A $>\mathrm{G}$ & Intron & & 5'-GAAAACGCACTTGCCCAGTTCGCCA[A/G] \\
& & & CATTCCCGCTATTTCCCAAAATATT-3'
\end{tabular}

Context sequence refers to the TaqMan probe binding the DNA. SNP, single nucleotide polymorphism.

detected with ECL-Prime (GE Healthcare Life Sciences) using ChemiDoc XRS (Bio-Rad Laboratories, Inc.). The expression levels of VEGFR2 were semi-quantitatively analyzed using ImageLab $^{\circledR} 5.1$ software (Bio-Rad Laboratories, Inc.) with vinculin as a loading control.

Flow experiments. The HUVECs were seeded at $7 \times 10^{5} / \mathrm{ml}$ into bifurcation flow-through slides (Integrated BioDiagnostics) and grown until confluence. The cell monolayer was perfused with medium for $19 \mathrm{~h}$, at a flow rate of $9.6 \mathrm{ml} / \mathrm{min}$, corresponding to a laminar shear stress of $10.2-10.8 \mathrm{dyne} / \mathrm{cm}^{2}$ in the straight main channel and a non-laminar shear stress of $\sim 6.3 \mathrm{dyne} / \mathrm{cm}^{2}$ to $\sim 0.5 \mathrm{dyne} / \mathrm{cm}^{2}$ in the channel distal to the bifurcation (4). The cells were stimulated with tumor necrosis factor (TNF)- $\alpha(2.5 \mathrm{ng} / \mathrm{ml}$; Miltenyi Biotec) for the final $2 \mathrm{~h}$ of flow.

Immunofluorescent staining. Following the flow experiment, the protein expression of VCAM-1, E-selectin and VEGFR2 was determined by immunocytochemical staining. The HUVECs were fixed with $4 \%$ formalin (Roth), permeabilized with $0.2 \%$ Triton X-100 (Sigma; Merck KGaA) in PBS, and blocked with 5\% horse serum (Gibco; Thermo Fisher Scientific, Inc.) in PBS. Staining was performed with anti-VCAM-1 (cat no. BBA5, CloneBBIG-V1, 1:100; R\&D Systems, Inc.), anti-E-selectin (cat. no. BBA16, Clone BBIG-E4, 1:100; R\&D Systems, Inc.) and anti-VEGFR2 (cat. no. sc-505, N-931; 1:100; Santa Cruz Biotechnology, Inc.) at room temperature for $1 \mathrm{~h}$ and visualized using Alexa Fluor 488-conjugated anti-mouse IgG (cat. no. A11001) or anti-rabbit IgG (cat. no. A11008) for $45 \mathrm{~min}$ at room temperature (1:500 in PBS; Molecular Probes; Thermo Fisher Scientific, Inc.).

To determine the average protein expression in the laminar and non-uniform shear stress regions within every slide, six visual fields at $\mathrm{x} 200$ magnification $\left(0.33 \mathrm{~mm}^{2}\right.$ each $)$ were selected from the laminar shear stress region and eight visual fields from the non-uniform shear stress regions (Fig. S1) (4). Digital images were captured using an inverted fluorescent microscope (Olympus) with image processing software (NIS Elements ${ }^{\circledR} 3.2$; Nikon). For every image, a threshold was set to define the positive fluorescent signal intensity of the entire image. Analyses were performed using Image ${ }^{\circledR} 1.48 \mathrm{v}$ software, and the corrected total cell fluorescence (CTCF) was calculated as follows: CTCF = integrated density - (area of selected cell x mean fluorescence of background) (30).
Adhesion assay. Adhesion assays were performed as described in previous studies (5,31). THP-1 monocytic cells (American Type Culture Collection; cat. no. TIB-202) were cultured in RPMI 1640 medium supplemented with $10 \%$ fetal calf serum, $2 \mathrm{mmol} / \mathrm{l}$ glutamine (Biochrom AG), $100 \mathrm{U} / \mathrm{ml}$ penicillin and $100 \mu \mathrm{g} / \mathrm{ml}$ streptomycin (both antibiotics from Gibco; Thermo Fisher Scientific, Inc.). The THP-1 cells used for adhesion assays were in passages 5-25. Following TNF- $\alpha$ stimulation $(2.5 \mathrm{ng} / \mathrm{ml})$, the HUVECs were perfused with 7,500,000 THP-1 monocytic cells for $1 \mathrm{~h}$ at $37^{\circ} \mathrm{C}$ in ECGM. Subsequently, any non-adhering THP-1 cells were flushed away with ECGM. The HUVECs with adhering THP-1 cells were fixed with $4 \%$ formalin, treated with $0.2 \%$ Triton $\mathrm{X}-100$ in PBS and stained with hematoxylin and eosin, which stains nuclei dark blue and the cytoplasm light red. The distinction between HUVECs and THP-1 cells was clear using this staining (Fig. 1B). For every slide, six visual fields at x200 magnification $\left(0.33 \mathrm{~mm}^{2}\right)$ were selected from the laminar shear stress region and eight visual fields were selected from the non-uniform shear stress regions. Digital images were captured using an inverted microscope (Olympus) with image processing software and the numbers of THP-1 cells per visual field were counted (NIS Elements ${ }^{\circledR}$ 3.2; Nikon).

Statistical analysis. Statistical analyses were conducted using SigmaPlot ${ }^{\circledR} 12.3$ (Systat Software, Inc). The Hardy-Weinberg equilibrium (HWE) of the occurrence and distribution in sex for three SNPs were assessed using Fisher's exact test or the $\chi^{2}$ test, respectively. Differences between the laminar and non-uniform shear stress regions were analyzed using the Wilcoxon Signed Rank test. Among the three genotype groups, differences in adhesion molecule expression, the expression of VEGFR2 and the number of adhered THP-1 cells were compared using Kruskal-Wallis one-way ANOVA on ranks with a post hoc test (Bonferroni). $\mathrm{P}<0.05$ was considered to indicate a statistically significant difference.

\section{Results}

Characteristics of the observed HUVECs. The HUVECs were collected from 113 individuals, comprising 61 men (54\%) and 52 women (46\%). The distribution of genotypes regarding the three SNPs was in accordance with the Hardy-Weinberg equilibrium, and the allele frequencies were similar to those in former studies (Fig. S2). There was no difference in the 
A

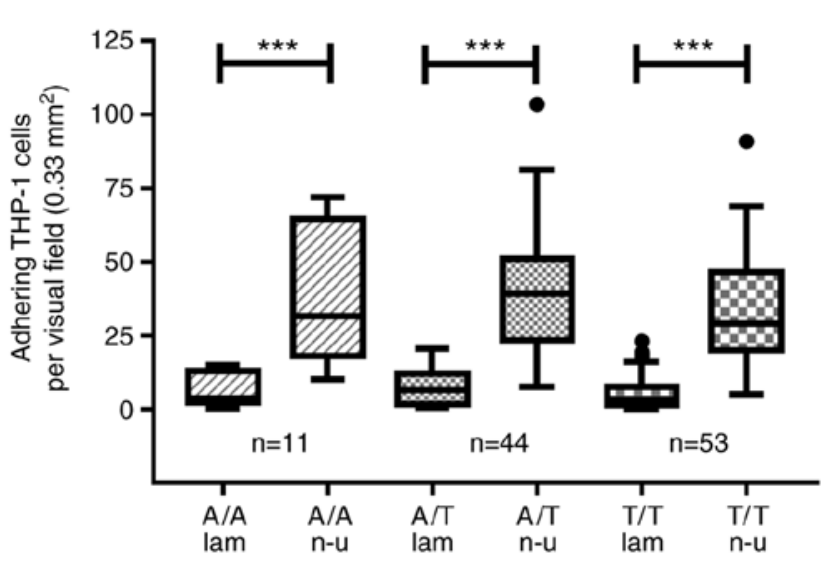

Adhesion rs2071559 A>G

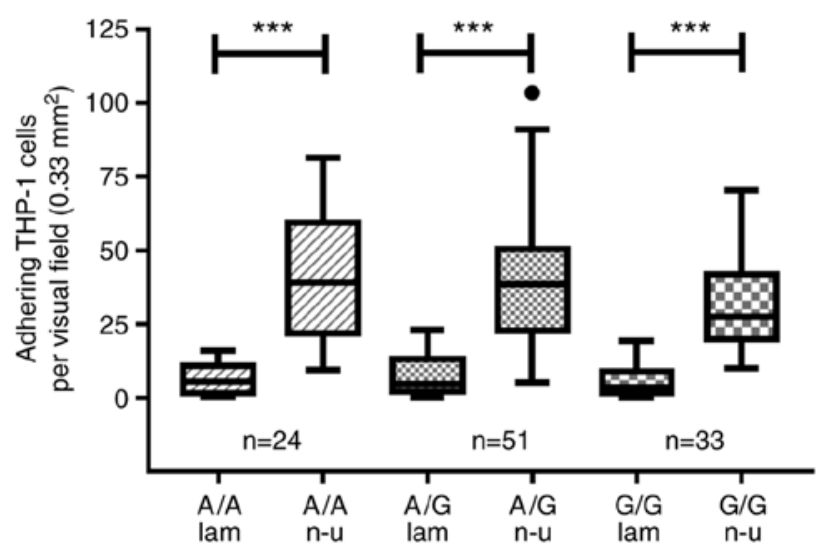

Adhesion rs2305948 C>T

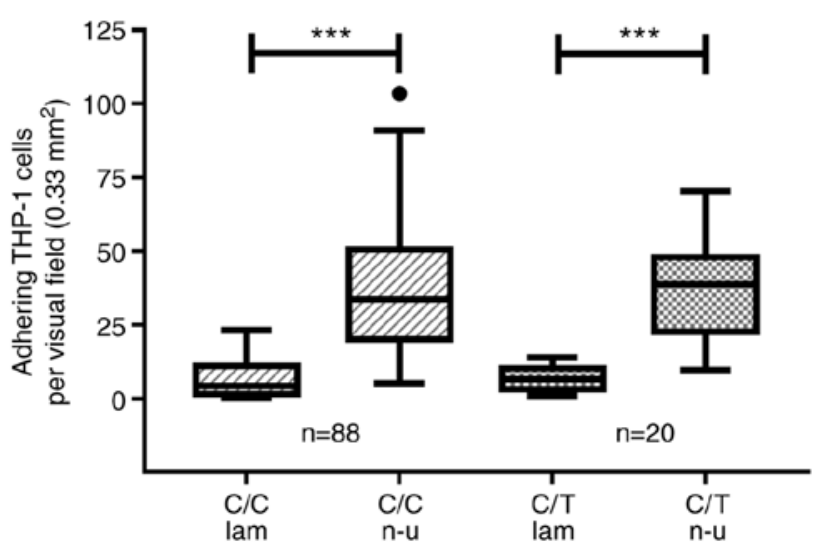

$\mathrm{B}$

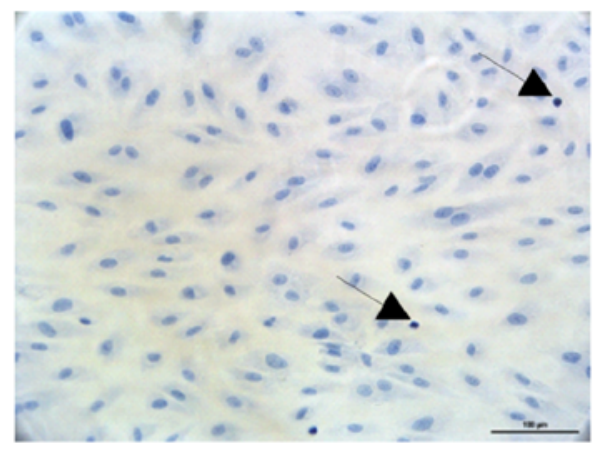

Laminar shear stress

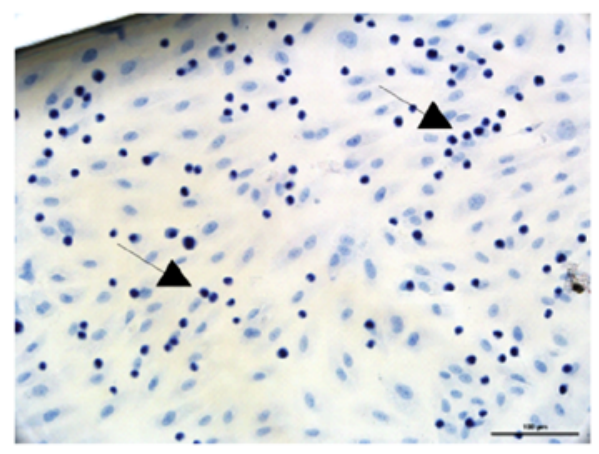

Non-uniform shear stress

Figure 1. THP-1 monocytic cell adhesion to flow-activated endothelial cells under laminar and non-uniform shear stress. Human umbilical vein endothelial cells were exposed to flow for $17 \mathrm{~h}$ followed by tumor necrosis factor- $\alpha$ stimulation for $2 \mathrm{~h}$ and perfused for an additional $1 \mathrm{~h}$ with 7,500,000 THP-1 monocytic cells. Cells were fixed and stained with hematoxylin and eosin. Data are expressed as the median with 25 th and 75 th percentiles. Whiskers indicate 5th and 95th percentiles (Tukey-style). (A) Results of adhesion assays in laminar and non-uniform shear stress regions in rs1870377 T>A; rs2071559 A>G and rs2305948 $\mathrm{C}>\mathrm{T}$, measured by Wilcoxon Signed Rank test. ${ }^{* * *} \mathrm{P}<0.001$. (B) Representative images of THP-1 adhesion in regions of laminar and non-uniform shear stress; images were captured at x200 magnification; the arrows point to THP-1 monocytic cells (scale bar, $100 \mu \mathrm{m}$ ). lam, laminar; n-u, non-uniform.

ratio of men to women among genotypes for all SNPs. No significant correlations were observed between any of the genotypes and being male, which is a cardiovascular risk factor (Table II). The homozygous T/T genotype in rs 2305948 $\mathrm{C}>\mathrm{T}$ was excluded from further analyses due to its sample size being too small (Fig. S2 and Table II). Even in a T allele dominant model, comparing the $\mathrm{C} / \mathrm{C}$ genotype with the
$\mathrm{C} / \mathrm{T}+\mathrm{T} / \mathrm{T}$ genotypes revealed no significant differences in the protein expression of VEGFR2, VCAM-1 or E-selectin (data not shown).

The results of the linkage analyses revealed that there was no disequilibrium among the three analyzed SNPs compared with the GWAS data of a European population; therefore, these SNPs were considered as independent variables $(28,29)$. 
Table II. SNP characteristics.

\begin{tabular}{|c|c|c|c|c|c|c|}
\hline \multirow[b]{2}{*}{ SNP } & \multirow[b]{2}{*}{ Genotype (n) } & \multicolumn{2}{|c|}{ Sex, n (\%) } & \multirow[b]{2}{*}{ P-value } & \multirow[b]{2}{*}{ Allele frequency } & \multirow[b]{2}{*}{ Global MAF } \\
\hline & & Male & Female & & & \\
\hline \multirow[t]{3}{*}{ rs1870377 T>A } & $\mathrm{AA}(11)$ & $5(45.5)$ & $6(54.5)$ & 0.790 & & \\
\hline & AT (44) & $24(54.5)$ & $20(45.5)$ & & $A=0.297$ & $A=0.212$ \\
\hline & TT (58) & $33(56.9)$ & $25(43.1)$ & & $\mathrm{T}=0.703$ & \\
\hline \multirow[t]{3}{*}{ rs2071559 A >G } & AA (33) & $20(60.6)$ & $13(39.4)$ & & & \\
\hline & AG (53) & $25(47.2)$ & $28(52.8)$ & 0.235 & $A=0.536$ & $A=0.499$ \\
\hline & GG (26) & 17 (65.4) & $9(34.6)$ & & $\mathrm{G}=0.464$ & \\
\hline \multirow[t]{3}{*}{ rs2305948 C>T } & CC (90) & $51(56.7)$ & $39(43.3)$ & & & \\
\hline & CT (21) & $10(47.6)$ & $11(52.4)$ & $0.612^{\mathrm{c}}$ & $\mathrm{C}=0.885$ & $\mathrm{~T}=0.153$ \\
\hline & TT (1) & $1(100)$ & $0(0)$ & & $\mathrm{T}=0.115$ & \\
\hline
\end{tabular}

No significant correlations were observed between genotype and male sex, a known cardiovascular risk factor. Statistical analysis was performed using $2 \times 3$ Fisher's exact test or $\chi^{2}$ test. $\mathrm{P}<0.05$ was considered to indicate a statistically significant difference. ${ }^{\mathrm{a} F i s h e r}$ 's exact

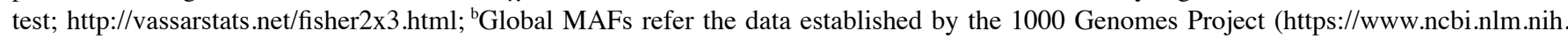
gov/projects/SNP/). ${ }^{c} \chi^{2}$ test between CC and CT. SNP, single nucleotide polymorphism; MAFs, minor allele frequencies.

Basal expression of VEGFR2 is not affected by SNPs in $V E G F R 2$. The basal expression levels of VEGFR2 under static conditions were semi-quantitatively evaluated by western blotting. The results revealed no significant differences among the three genotypes, although the highest median expression of VEGFR2 was observed in A/A in rs2071559 A $>$ G compared with that in the other two genotypes (Fig. 2; one-way ANOVA on ranks 0.096).

Flow-induced expression of VEGFR2 is not affected by SNPS. The expression levels of VEGFR2 were evaluated in HUVECs cultured under non-uniform shear stress and laminar shear stress for $19 \mathrm{~h}$. The collective VEGFR2 expression data from samples with any genotype are shown in Fig. 3, grouped according to flow type (Fig. 3A). In regions of non-uniform shear stress, the HUVECs expressed significantly lower levels of VEGFR2 compared with that in regions of atheroprotective laminar shear stress $(\mathrm{P}<0.001$; Fig. 3A), independent of the genotypes of any the SNPs. There was no significant difference in expression of VEGFR2 under either laminar or non-uniform shear stress among the three genotypes of any the SNPs (Fig. 4).

Expression of endothelial cell activation markers is affected by SNPs in VEGFR2. The HUVECs were cultured under non-uniform or laminar shear stress conditions and stimulated with TNF- $\alpha$. The protein expression levels of adhesion molecules (i.e., VCAM-1 and E-selectin, markers for endothelial activation) were quantified by means of fluorescent immunocytochemical staining (Fig. 5). As expected, the expression of VCAM-1 was significantly higher in the non-uniform regions compared with that in laminar shear stress regions in all datasets analyzed using the Wilcoxon Signed Rank test.

In rs1870377 T>A, significant differences were observed between the different genotypes: Under laminar shear stress, the highest median expression of VCAM-1 was observed in $\mathrm{T} / \mathrm{T}$, followed by a lower expression in T/A (67\% of T/T), and the lowest expression in A/A (18\% of T/T) genotypes. This showed

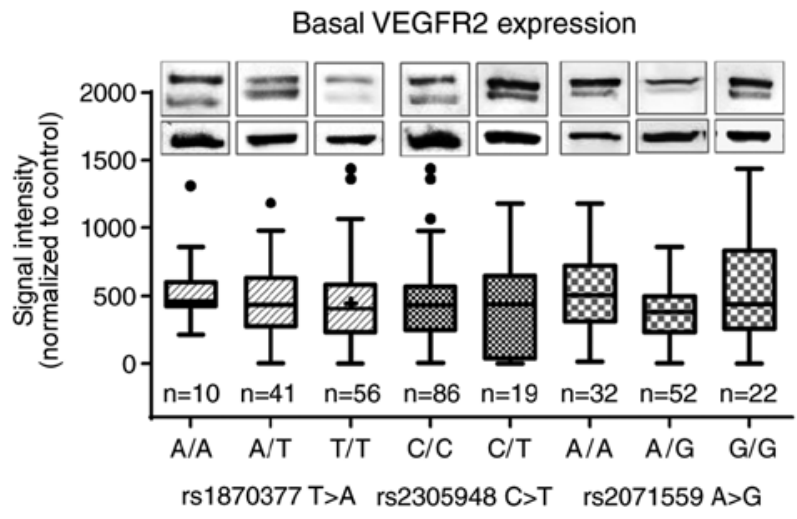

Figure 2. Basal expression of VEGFR2. Human umbilical vein endothelial cells were cultured under static conditions. Cells were harvested for protein measurement and semidry western blotting was performed for semi-quantitative analyses of VEGFR2, with vinculin as a loading control. Representative western blot images show the expression of VEGFR2 (upper double-band) and vinculin (lower band) of different donors. Data are expressed as the median with 25th and 75th percentiles (Tukey-style). Comparison between genotypes of one SNP was measured by one-way ANOVA on Ranks (rs1870377 T>A, rs2071559 A $>$ G) or the Mann-Whitney Rank Sum test (rs2305948 C>T). VEGFR2, vascular endothelial growth factor receptor 2

an increased expression of VCAM-1 with increasing content of the $\mathrm{T}$ allele (one-way ANOVA on Ranks 0.052). This trend was strengthened by non-uniform shear stress conditions; the expression of VCAM-1 was significantly lower in the A/A genotype (74\% reduction) than that in the $\mathrm{T} / \mathrm{T}$ genotype (one-way ANOVA on Ranks 0.023), with intermediate expression in the heterozygous $\mathrm{A} / \mathrm{T}$ (40\% reduction) genotype (Fig. 6A). A tendency of increased median expression of VCAM-1 with increasing G-content was observed in rs2071559 A>G, but the differences were not statistically significant $(52 \%$ reduction in A/A under laminar flow pattern and 63\% under non-uniform shear stress; Fig. 7A). Furthermore, no significant differences in VCAM-1 were observed among the different genotypes in rs2305948 C $>$ T (data not shown). 


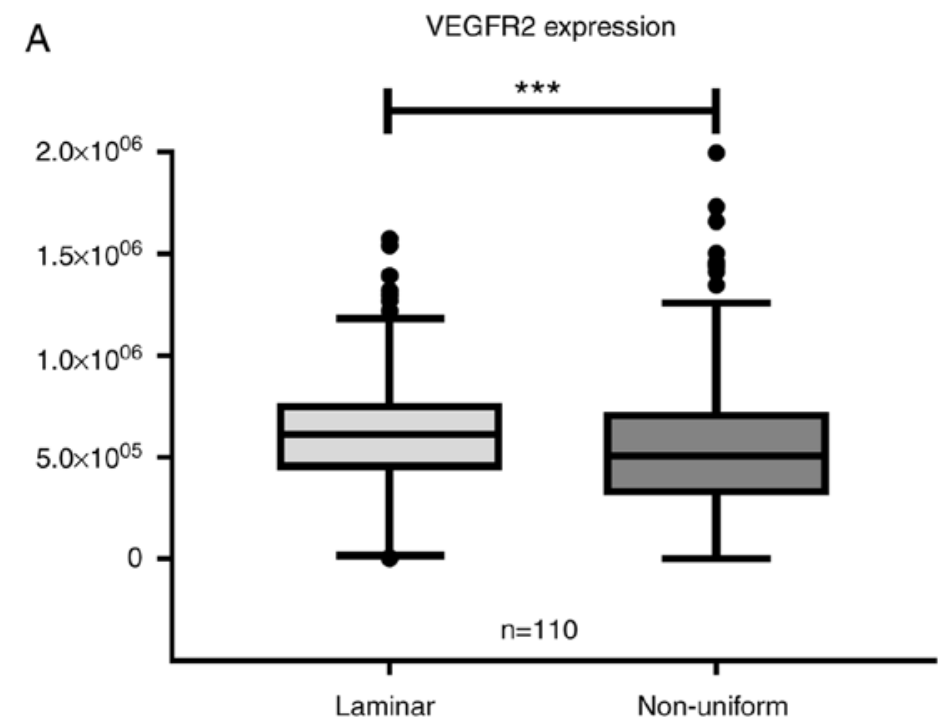

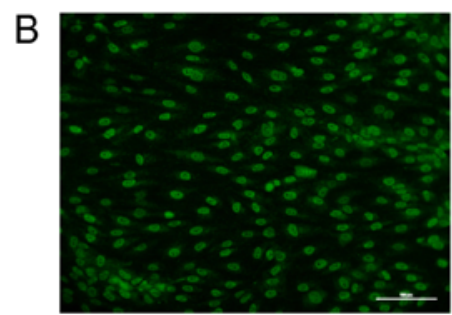

Laminar shear stress

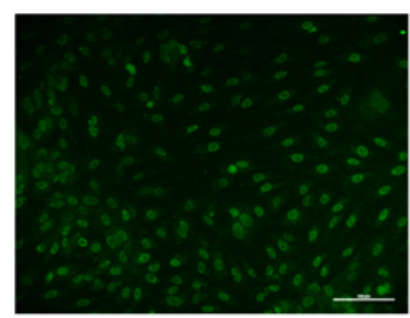

Non-uniform shear stress

Figure 3. Expression of VEGFR2 under flow conditions. (A) Expression of VEGFR2 under laminar and non-uniform shear stress conditions, independently of the genotype; human umbilical vein endothelial cells were exposed to flow for $17 \mathrm{~h}$ followed by tumor necrosis factor- $\alpha$ stimulation for $2 \mathrm{~h}$. Cells were fixed and stained for VEGFR2; data are expressed as the median with 25th and 75 th percentiles (Tukey-style); ${ }^{* * *} \mathrm{P}<0.001$. Differences between groups were measured using Wilcoxon Signed Rank Test. (B) Representative images of VEGFR2 staining of regions with laminar and non-uniform shear stress (scale bar, $100 \mu \mathrm{m}$ ). VEGFR2, vascular endothelial growth factor receptor 2; CTCF, corrected total cell fluorescence.
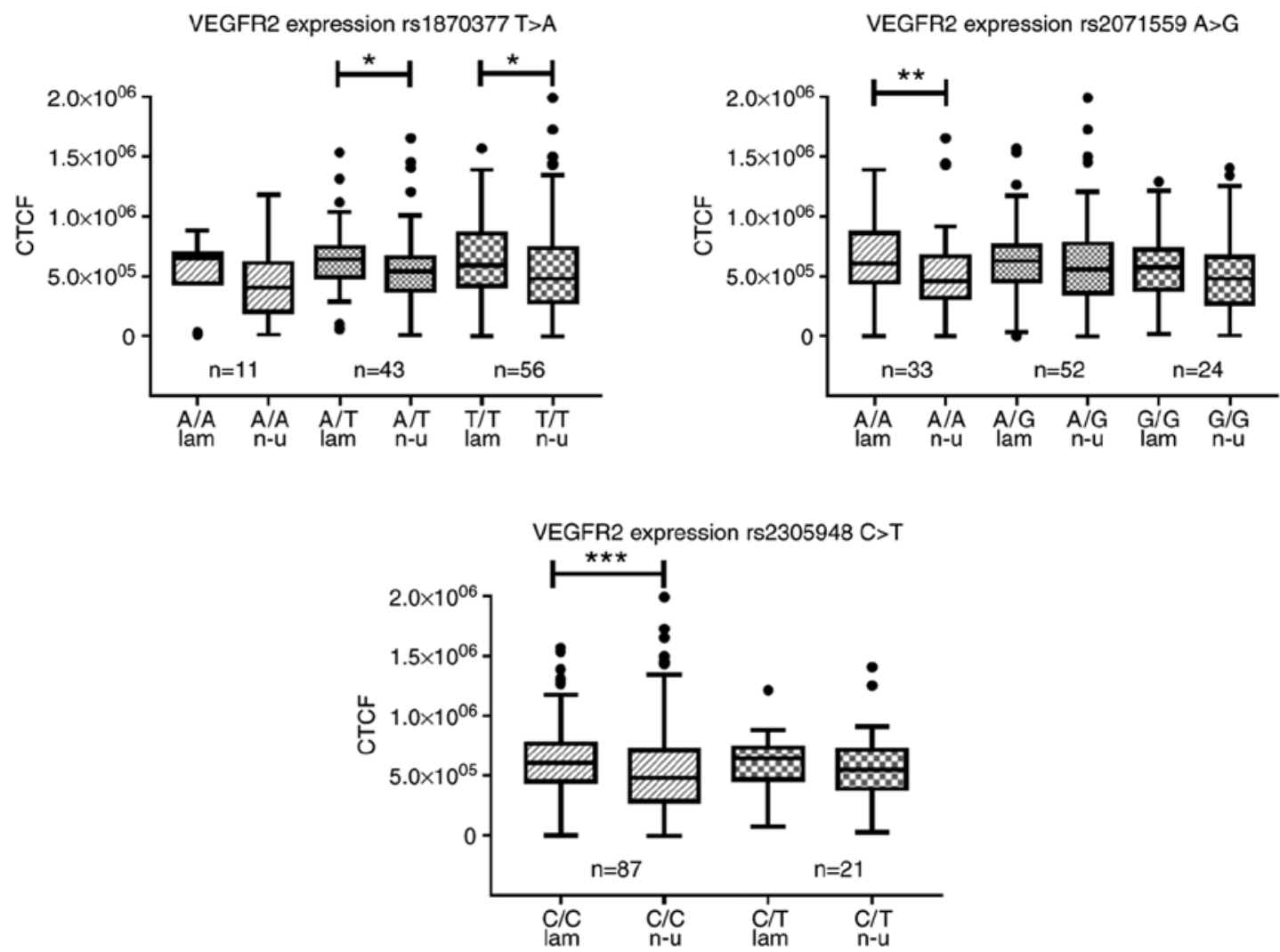

Figure 4. Expression of VEGFR2 under different flow conditions. Human umbilical vein endothelial cells were exposed to flow for $17 \mathrm{~h}$ followed by tumor necrosis factor- $\alpha$ stimulation for $2 \mathrm{~h}$. Cells were fixed and stained for VEGFR2. Data are expressed as the median with 25th and 75th percentiles. Whiskers indicate 5th and 95th percentiles (Tukey-style); ${ }^{*} \mathrm{P}<0.05,{ }^{* *} \mathrm{P}<0.01,{ }^{* * *} \mathrm{P}<0.001$. No significant differences, measured by Kruskal-Wallis one-way ANOVA on Ranks, were observed under atheroprotective or atheroprone shear stress in any of the analyzed SNPs. VEGFR2, vascular endothelial growth factor receptor 2; CTCF, corrected total cell fluorescence; lam, laminar; n-u, non-uniform.

Similarly, significant flow-dependent differences were observed in the expression of E-selectin. With the exception of the A/A genotype of rs1870377 T>A, laminar shear stress regions showed a significant reduction in E-selectin compared with non-uniform shear stress regions (Fig. 5). Comparable to the expression of VCAM-1, the lowest expression of E-selectin 

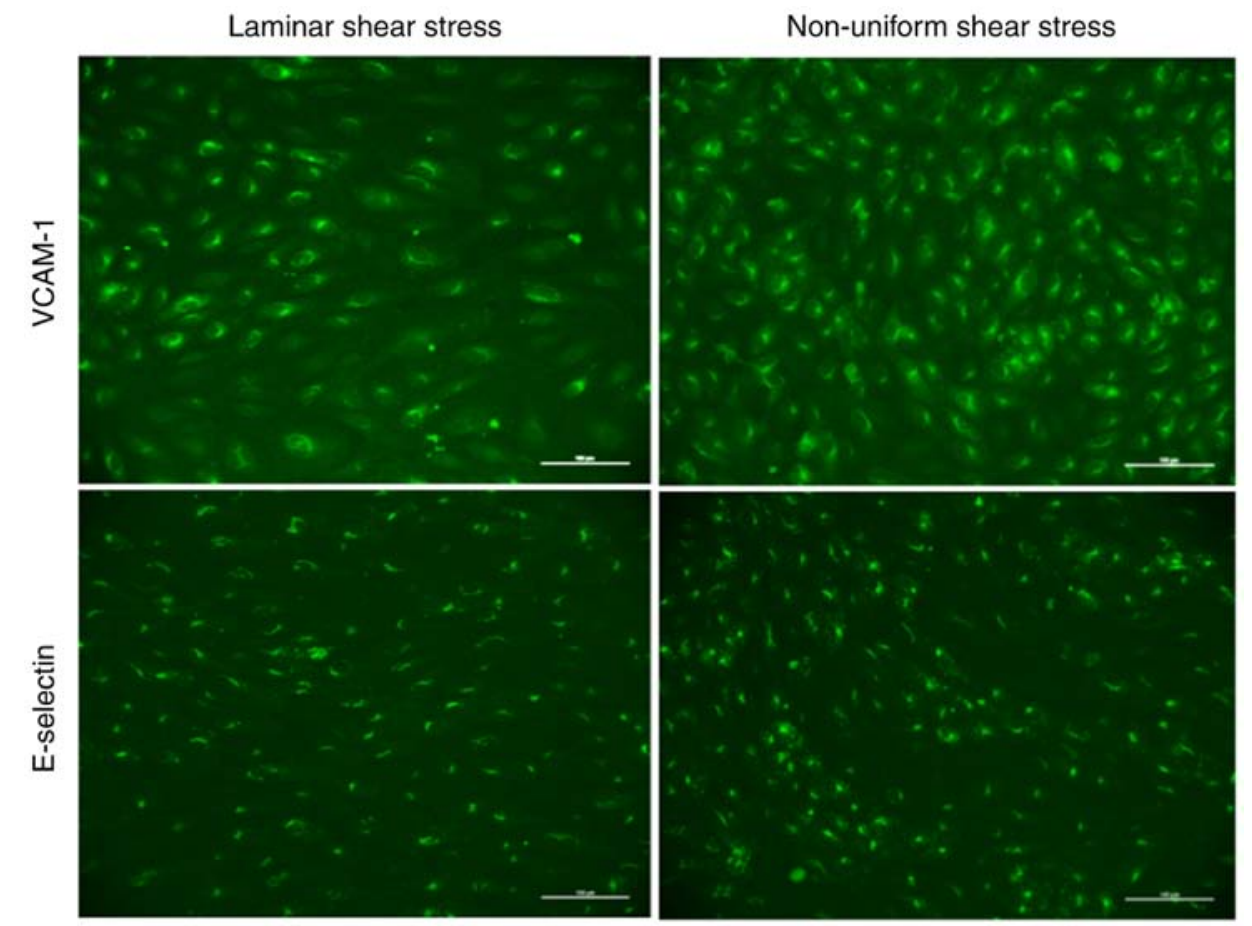

Figure 5. Expression of VCAM-1 and E-selectin under different shear stress conditions. Human umbilical vein endothelial cells were exposed to flow for $17 \mathrm{~h}$ followed by tumor necrosis factor- $\alpha$ stimulation for $2 \mathrm{~h}$. Cells were fixed and stained for VCAM-1 or E-selectin. Representative images show VCAM- 1 and E-selectin staining of regions with laminar and non-uniform shear stress; images were captured at x200 magnification (scale bar, $100 \mu \mathrm{m}$ ). VCAM-1, vascular cell adhesion molecule-1.

in $\mathrm{rs} 1870377 \mathrm{~T}>\mathrm{A}$ was in the $\mathrm{A} / \mathrm{A}$ genotype ( $70 \%$ reduction) under laminar and non-uniform shear stress conditions, although the difference was not statistically significant (Fig. 6B). In rs2071559 A $>$ G, the A/A genotype showed similar expression to VCAM-1, with the lowest expression of E-selectin under laminar ( 60\% reduction) and non-uniform (57\% reduction) shear stress conditions (one-way ANOVA on Ranks, 0.093/0.121) compared with that in the G/G genotype (Fig. 7B). No significant differences were observed in rs2305948 C $>$ T (data not shown).

SNPs do not influence the adhesion of THP-1 monocytic cells to an endothelial cell monolayer under flow conditions. The adhesion of THP-1 monocytic cells was analyzed in an in vitro flow model after $2 \mathrm{~h}$ of TNF- $\alpha$ stimulation. As expected, the adhesion of THP-1 cells significantly increased in regions of non-uniform shear stress in all analyzed SNPs compared with that in atheroprotective laminar shear stress conditions, although no significant differences in THP-1 adhesion were observed among the distinct genotypes in any of the SNPs (Fig. 1).

\section{Discussion}

The aim of the present study was to investigate the association between SNPs in VEGFR2 and atherogenesis on a cellular basis. To date, only a small number of studies have investigated a possible influence of SNPs in VEGFR2 on the occurrence of atherosclerosis or associated complications, such as myocardial infarction or stroke. No previous studies have addressed the cellular mechanism of the first step of atherogenesis in endothelial dysfunction. Therefore, the present study performed flow simulation experiments, in which regions of high laminar shear stress and non-uniform shear stress were readily differentiated within an in vitro flow chamber model. The region of laminar shear stress has a strictly laminar flow pattern, and these regions were identified throughout the straight main channel, whereas regions of non-uniform shear stress were located distal to the bifurcation, characterized by a reduced flow rate and perturbed shear pattern with a steep shear stress gradient in a direction transversal to the flow (4).

Quiescent growth factor receptors in the absence of their ligands are preferentially localized on the plasma membrane $(32,33)$. Ligand binding and receptor activation in the majority of cases leads to receptor internalization (34). Growth factor receptors, such as VEGFR2, are either recycled back to the plasma membrane or degraded, via ubiquitinylation by c-Cbl (35), following signal transduction (36). Only $60 \%$ of VEGFR2 molecules are located at the plasma membrane, with the remaining $40 \%$ localized in endosomes (37). The process of internalization may be critical for protecting VEGFR2 against shedding (38). The internalized VEGFR2 interacts with the transcription factor $\mathrm{Sp} 1$, which is known to be implicated in angiogenesis. It has also been shown that nuclear VEGFR2 is phosphorylated in proliferating cells. Furthermore, hypoxic stimulation increases the nuclear localization of total VEGFR2, whereas phosphorylated VEGFR2 remains predominantly perinuclear (39-41). Additionally, Domingues et al showed that nuclear VEGFR2 can act as a transcription factor regulating its own expression (42).

The phosphorylation and subsequent activation of VEGFR2 by fluid shear stress are dependent on PECAM-1 and VE-cadherin via several adapter molecules (43). Shay-Salit et al observed a rapid nuclear translocation of VEGFR2 following the onset of laminar flow, in addition to a quiescent mechano- 
A

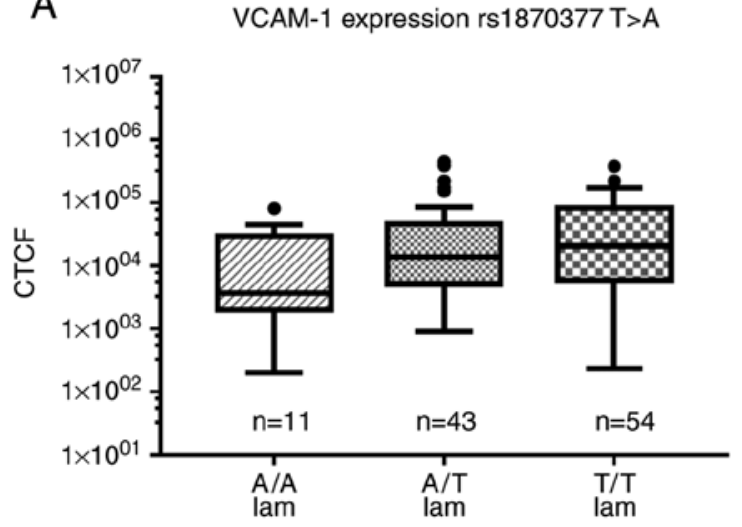

B

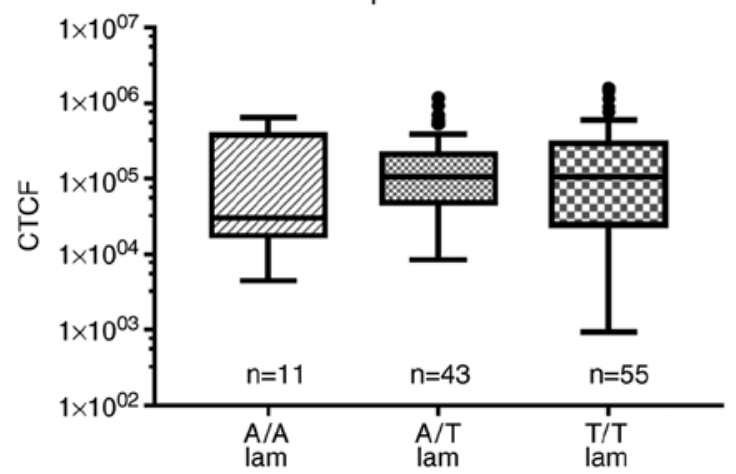

VCAM-1 expression rs1870377 T>A

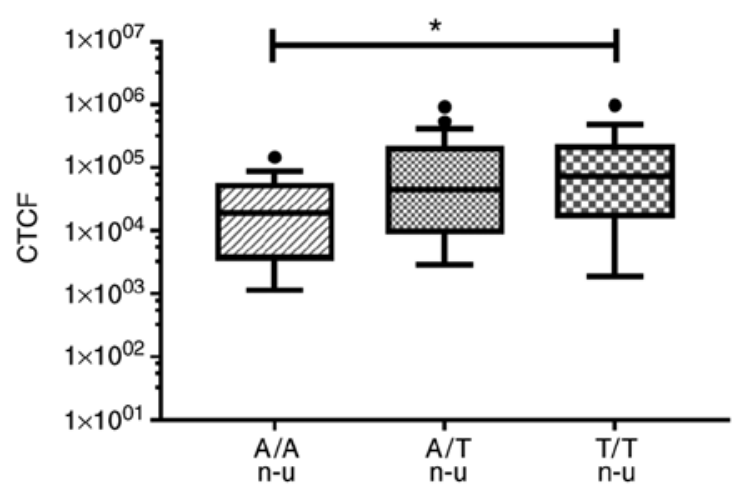

E-selectin expression rs1870377 T>A

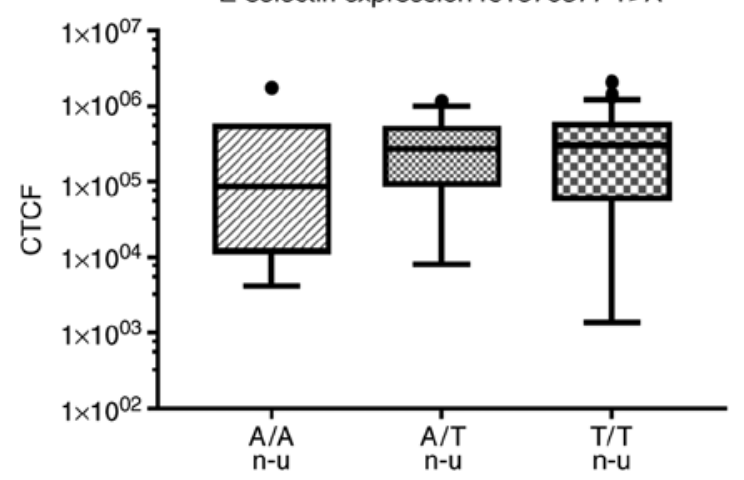

Figure 6. VCAM-1 and E-selectin in rs1870377 T>A. Expression of (A) VCAM-1 and (B) E-selectin in rs1870377 T>A. Human umbilical vein endothelial cells were exposed to flow for $17 \mathrm{~h}$ followed by tumor necrosis factor- $\alpha$ stimulation for $2 \mathrm{~h}$. Cells were fixed and stained for VCAM-1 or E-selectin. Significant differences in the expression of VCAM-1 were observed between A/A and T/T genotypes under non-uniform shear stress, measured by Kruskal-Wallis one-way ANOVA on Ranks (0.023) with a post-hoc test (Bonferroni). Data are expressed as the median with 25th and 75th percentiles. Whiskers indicate 5th and 95th percentiles (Tukey-style). "P<0.05. VCAM-1, vascular cell adhesion molecule-1; CTCF, corrected total cell fluorescence; lam, laminar; n-u, non-uniform.

sensory complex during sustained laminar flow conditions (44). In the present study, the results obtained by immunofluorescence in the model of different flow conditions revealed an overall decreased expression of VEGFR2 in regions of non-uniform shear stress, regardless of genotype. However, whether the receptor was degraded or internalized was not elucidated.

Rs1870377 $\mathrm{T}>\mathrm{A}$ and $\mathrm{rs} 2305948 \mathrm{C}>\mathrm{T}$ are located in the extracellular region at the third and fifth Ig domain. This affects the primary protein structure and its ligand binding properties due to polymorphisms of the amino acids (Table II). An increased risk of CVD for carriers of the A/A genotype of rs1870377 $\mathrm{T}>\mathrm{A}$ has been demonstrated in case-control studies, arguing that the SNP impairs VEGF binding efficiency to its receptor due to conformational changes of VEGFR2 (20).

Rs2071559 A $>\mathrm{G}$ is located at the VEGFR2 promotor region and leads to structural alterations of the binding site for the transcription factor E2F, which possibly leads to alterations in the expression of VEGFR2. Wang et al hypothesized that the polymorphisms lead to a conformational change, thereby influencing the binding affinity of VEGFR2 to VEGF, leading to dysfunctional signal transduction (20). However, the present study did not analyze VEGF receptor binding. In the population examined, the basal expression of VEGFR2 in HUVECs showed no significant differences in any of the SNPs. A comparison of the basal expression of VEGFR2 in in vitro endothelial cells with an in vivo study of serum levels in patients should be considered with caution.
Kariž and Petrovič showed a higher risk for myocardial infarction (MI) for a genotype with reduced levels of VEGFR2 (i.e., $\mathrm{G} / \mathrm{G}$ of rs2071559 A>G) (22) and others have suggested that the reduced expression of VEGFR2 is associated with a higher risk profile for CVD (20), which is in line with the observation in the present study of reduced expression of VEGFR2 under non-uniform shear stress conditions. The results indicated that a decreased signal of VEGFR2 may be one factor underlying the pathologic conditions of non-uniform shear stress.

In further experimental settings, the present study analyzed the expression of adhesion molecules, in addition to THP-1 monocyte adhesion, focusing on the different genotypes within the VEGFR2 SNPs. Our previous study described the direct impact of the expression of VEGFR2 on the expression of adhesion molecules in HUVECs under non-uniform shear stress (14). A direct link between polymorphisms in VEGFR2 and the activation and expression of adhesion molecules has not been discussed in former studies. However, VEGFR2 is associated with adhesion molecule expression, as stimulation of VEGFR2 can induce the phosphoinositide 3-kinase (PI3K)-Akt and $\mathrm{NF}-\kappa \mathrm{B}$ pathway $(11,45,46)$, which in turn leads to the de novo synthesis of molecules, including VCAM-1 and E-selectin.

From the results of the present study, the presence of endothelial dysfunction in an in vitro bifurcation model was confirmed; the A/A genotype for SNP rs1807377 T>A was identified as having a significantly lower adhesion molecule expression. Therefore, this genotype may attenuate endothelial 
A

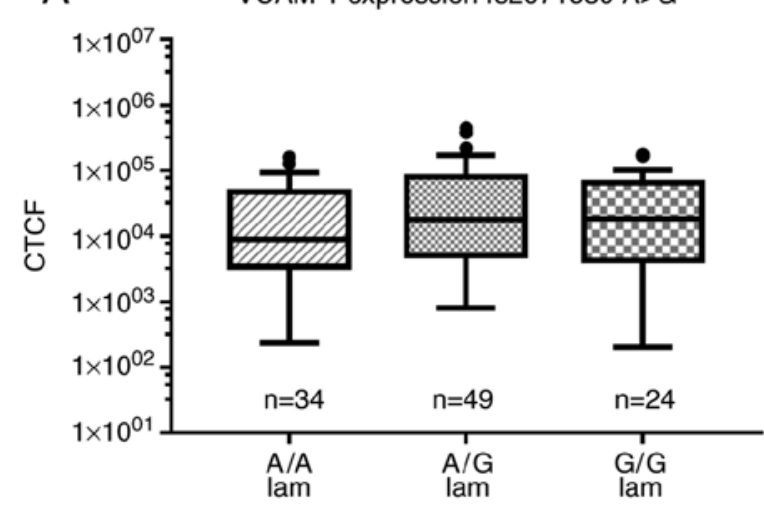

B

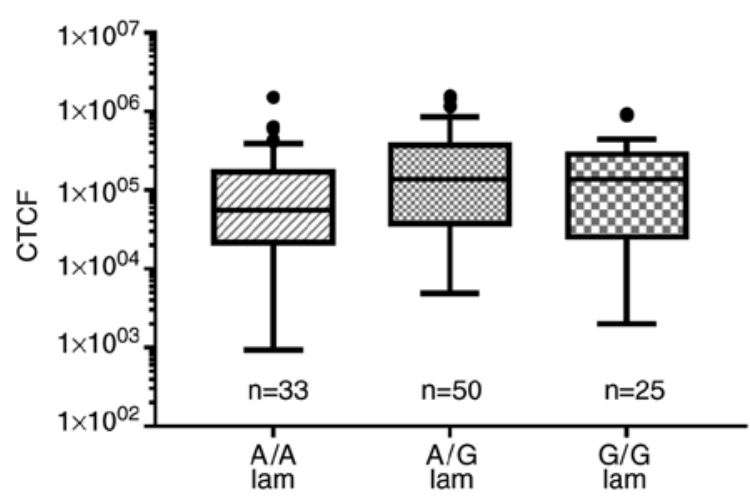

VCAM-1 expression rs2071559 A>G

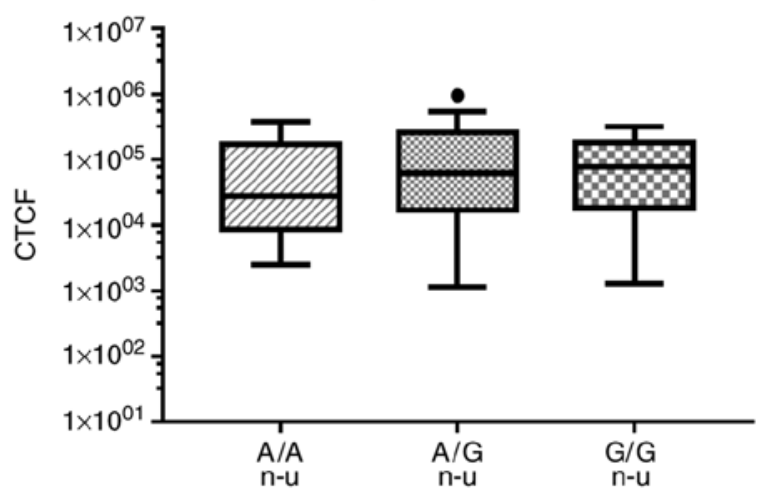

E-selectin expression rs2071559 A>G

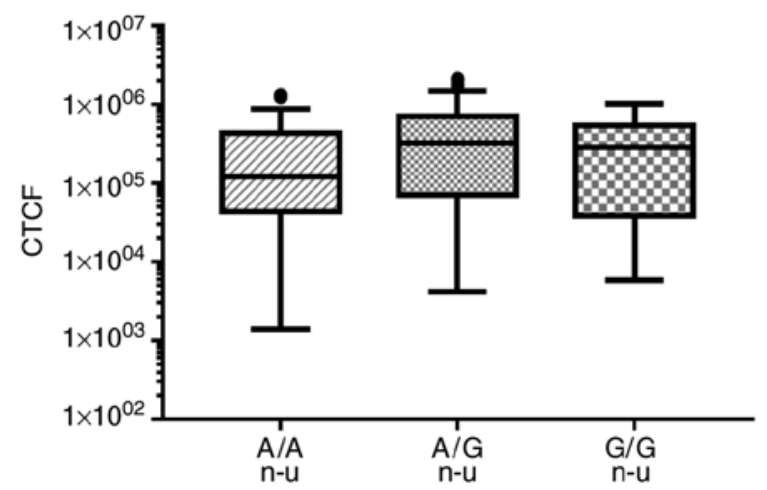

Figure 7. VCAM-1 and E-selectin in rs2071559 A>G. Expression of (A) VCAM-1 and (B) E-selectin in rs2071559 A>G. Human umbilical vein endothelial cells were exposed to flow for $17 \mathrm{~h}$ followed by tumor necrosis factor- $\alpha$ stimulation for $2 \mathrm{~h}$. Cells were fixed and stained for VCAM-1 or E-selectin. Data are expressed as the median with 25 th and 75 th percentiles. Whiskers indicate 5 th and 95 th percentiles (Tukey-style). VCAM-1, vascular cell adhesion molecule-1; CTCF, corrected total cell fluorescence; lam, laminar; n-u, non-uniform.

dysfunction in atherosclerosis-prone regions and may have a protective effect against the development of atherosclerosis and CVD. This is in line with reports from two Chinese groups: In rs1870377 $\mathrm{T}>\mathrm{A}$, the A allele leads to reduced vulnerability to CVD, whereas the T allele may have the opposite effect $(47,48)$, particularly when considering the haplotypes. However, contradictory results have also been reported in reports: A subpopulation of patients with diabetes mellitus type 2 had a reduced risk of CVD with the T allele, and another subpopulation of patients who smoke, as the classical risk factor for CVD, also had a significant reduction in risk of CVD with the T allele, compared with the in non-smokers $(47,48)$. These contradictory results within one study indicate the difficulties in interpreting the results of SNP analyses for a disease like atherosclerosis with a wide variety of influencing factors, for example, genetic predisposition, comorbidity factors and lifestyle.

The $\mathrm{G} / \mathrm{G}$ genotype of $\mathrm{rs} 2071559 \mathrm{~A}>\mathrm{G}$ showed increased median expression of VCAM-1 and E-selectin, leading to increased endothelial activation, thereby supporting the conclusion that the G allele of the SNP may be a risk allele for CVD. Kariž and Petrovič found a significant correlation between $\mathrm{MI}$ and the G/G genotype in rs2071559 A>G in patients with type 2 diabetes, with a 1.6-fold higher risk of $\mathrm{MI}$ in G/G carriers (22). Therefore, the results from Kariž and Petrovič and the present study do not agree with the results from Li et al, which showed a reduced risk of CVD for carriers of the $\mathrm{G}$ allele in rs2071559 $\mathrm{A}>\mathrm{G}$ compared with carriers with the corresponding A allele (47), and those of Zhang et al, which found a negative correlation between rs2071559 A>G and intima-media thickness for $\mathrm{G}$ allele samples (21).

The third SNP analyzed in the present study was rs 2305948 $\mathrm{C}>\mathrm{T}$. Again, the results from previous studies analyzing potential associations of this SNP with CVD are conflicting. Zhang et al reported that the $\mathrm{T}$ allele was associated with increased risk for stroke (21), and Li et al confirmed this from analyzing data of a Chinese population adjusted for cardiovascular risk factors (47). Additionally, Liu et al analyzed this SNP regarding the risk for CVD in a Han Chinese population. Without adjustment for additional risk factors, individuals with the $\mathrm{C}$ allele showed a significantly higher risk for CVD. However, following regression analyses for the individual risk factors, such as smoking, diabetes, hypertension or alcohol abuse, the $\mathrm{C}$ allele was shown to be protective against CVD in smoking and non-smoking patients. The individual analyses of patients with and without hypertension, and of patients with or without diabetes, also showed a protective effect of the $\mathrm{C}$ allele against CVD (48). As the T/T genotype was rare, with only one sample, it was not possible to compare the two divergent homozygous genotypes in the present study, where the most pronounced differences were expected. The comparison between $\mathrm{C} / \mathrm{C}$ and $\mathrm{C} / \mathrm{T}$ showed no significant difference in any of the experimental settings.

Regarding discrepancies between former studies and the present study, it is important to consider that the in vitro model 
used in the present study simulates the early events of atherogenesis. This may not allow a direct comparison with the cited association studies in fully developed CVD having additional risk factors. Atherosclerosis and CVD are complex diseases with a large number of subtle contributing factors that may influence the severity or outcome in different patients. Considering that inherited factors, genetic markers and epigenetics influence the diverse regulation of VEGFR2 and endothelial cell homeostasis, the comparability of results in this field of research is impeded. Taken together, compared with most clinical case-control studies, the set of 113 samples in the present study was relatively small. Furthermore, due to the anonymization of the samples, information about the donors, including ethnic background, age of the mother, complications at birth, or any accompanying diseases, are missing. The majority of subjects in the present study were reportedly central Europeans. Compared with an East Asian population, a European population appears to have a higher frequency of $\mathrm{T}$ in rs1870377 $\mathrm{T}>\mathrm{A}$ and $\mathrm{C}$ in rs2305948 C>T (49).

As the results of the present study are conflicting with those of former studies in a Chinese population $(16,48)$, there may be variations in gene expression due to a variety of factors, including ethnicity, which affected the results obtained (50). This may explain the large variability within the population; and despite a large proportional reduction of adhesion molecule expression, statistical significance was not detected.

In conclusion, the present study provides new evidence that the three investigated SNPs may offer potential as novel risk markers for CVD and warrant further investigation in the pathogenesis of atherosclerosis and CVD. The A/A genotype of rs1870377 $\mathrm{A}>\mathrm{T}$ appeared to be atheroprotective, whereas the $\mathrm{G} / \mathrm{G}$ genotype of rs2071559 A>G may enhance endothelial dysfunction. The discrepant findings between the observations in the present study at a cellular level and those from clinical studies suggest that any genetic polymorphism would be strongly affected by additional risk factors for CVD, including type 2 diabetes, hypertension, hypercholesterolemia and smoking. In addition, SNPs may influence collateral development not only individually but also when acting together with other SNPs, through gene haplotype networks.

\section{Acknowledgements}

The authors would like to thank Mrs. Jaziri, Mrs. Flick and Mrs. Kloos (Laboratory for Molecular and Experimental Cardiology, Department of Medicine-2, University Hospital Erlangen) for their technical support in this study, and Mrs. Zwenger (Institute of Human Genetics, University Hospital Erlangen) for SNP sequencing.

\section{Funding}

The present study was funded by the ELAN fund, Friedrich-Alexander-Universität Erlangen-Nürnberg (grant. no. ELAN-13-1171-Urschel). The study was designed, conducted and written independently from the funding institution.

\section{Availability of data and materials}

The datasets are available from the corresponding author upon reasonable request.

\section{Authors' contributions}

KU and BD conceived and designed the study. NMS and KU collected and analyzed the data. KU and NMS wrote the manuscript. MT and DRS substantively revised the researched articles and were involved in the interpretation of results. FMS provided the umbilical cords and contributed to the interpretation of results. SA revised the results from a clinicians view, thereby being involved in analyses and interpretation of the results in the specific professional context. SA, BD and MT critically revised the manuscript for important intellectual content. FP was involved in data collection and interpretation of the results. All authors read and approved the final manuscript.

\section{Ethics approval and consent to participate}

The collection of human material and the study protocol were approved by the Ethics Committee of the Medical Department of the Friedrich-Alexander-Universität Erlangen-Nürnberg (case no. 246_13B). Written consent was obtained from all women prior to donation.

\section{Patient consent for participation}

Not applicable.

\section{Competing interests}

The authors declare that they have no competing interests.

\section{References}

1. Slager CJ, Wentzel JJ, Gijsen FJ, Schuurbiers JC, van der Wal AC, van der Steen AF and Serruys PW: The role of shear stress in the generation of rupture-prone vulnerable plaques. Nat Clin Pract Cardiovasc Med 2: 401-407, 2005.

2. Li YS, Haga JH and Chien S: Molecular basis of the effects of shear stress on vascular endothelial cells. J Biomech 38: 1949-1971, 2005.

3. Wasserman SM, Mehraban F, Komuves LG, Yang RB, Tomlinson JE, Zhang Y, Spriggs F and Topper JN: Gene expression profile of human endothelial cells exposed to sustained fluid shear stress. Physiol Genomics 12: 13-23, 2002.

4. Cicha I, Beronov K, Ramirez EL, Osterode K, Goppelt-Struebe M, Raaz D, Yilmaz A, Daniel WG and Garlichs CD: Shear stress preconditioning modulates endothelial susceptibility to circulating TNF-alpha and monocytic cell recruitment in a simplified model of arterial bifurcations. Atherosclerosis 207: 93-102,2009.

5. Urschel K, Worner A, Daniel WG, Garlichs CD and Cicha I: Role of shear stress patterns in the TNF- $\alpha$-induced atherogenic protein expression and monocytic cell adhesion to endothelium. Clin Hemorheol Microcirc 46: 203-210, 2010.

6. Pan S: Molecular mechanisms responsible for the atheroprotective effects of laminar shear stress. Antioxid Redox Signal 11: 1669-1682, 2009.

7. Tzima E, Irani-Tehrani M, Kiosses WB, Dejana E, Schultz DA, Engelhardt B, Cao G, DeLisser H and Schwartz MA: A mechanosensory complex that mediates the endothelial cell response to fluid shear stress. Nature 437: 426-431, 2005.

8. Holmes K, Roberts OL, Thomas AM and Cross MJ: Vascular endothelial growth factor receptor-2: Structure, function, intracellular signalling and therapeutic inhibition. Cell Signal 19: 2003-2012, 2007.

9. Shalaby F, Rossant J, Yamaguchi TP, Gertsenstein M, Wu XF, Breitman ML and Schuh AC: Failure of blood-island formation and vasculogenesis in Flk-1-deficient mice. Nature 376: 62-66, 1995

10. Fong GH, Rossant J, Gertsenstein M and Breitman ML: Role of the Flt-1 receptor tyrosine kinase in regulating the assembly of vascular endothelium. Nature 376: 66-70, 1995. 
11. Wang Y, Flores L, Lu S, Miao H, Li YS and Chien S: Shear stress regulates the Flk-1/Cbl/PI3K/NF- $\kappa$ B pathway via actin and tyrosine kinases. Cell Mol Bioeng 2: 341-350, 2009.

12. Lim HS, Blann AD, Chong AY, Freestone B and Lip GY: Plasma vascular endothelial growth factor, angiopoietin-1, and angiopoietin-2 in diabetes: Implications for cardiovascular risk and effects of multifactorial intervention. Diabetes Care 27: 2918-2924, 2004.

13. Petrovic D: The role of vascular endothelial growth factor gene as the genetic marker of atherothrombotic disorders and in the gene therapy of coronary artery disease. Cardiovasc Hematol Agents Med Chem 8: 47-54, 2010.

14. Urschel K, Garlichs CD, Daniel WG and Cicha I: VEGFR2 signalling contributes to increased endothelial susceptibility to TNF- $\alpha$ under chronic non-uniform shear stress. Atherosclerosis 219: 499-509,2011

15. Howell W, Ali S, Rose-Zerilli M and Ye S: VEGF polymorphisms and severity of atherosclerosis. J Med Genet 42: 485-490, 2005.

16. Zhang LJ, Zhang YQ, Han X, Zhang ZT and Zhang ZQ Association of VEGFR-2 Gene polymorphisms with clopidogrel resistance in patients with coronary heart disease. Am J Ther 23 e1663-e1670, 2016.

17. Hermann MM, van Asten F, Muether PS, Smailhodzic D, Lichtner P, Hoyng CB, Kirchhof B, Grefkes C, den Hollander AI and Fauser S: Polymorphisms in vascular endothelial growth factor receptor 2 are associated with better response rates to ranibizumab treatment in age-related macular degeneration. Ophthalmology 121: 905-910, 2014.

18. Jain L, Sissung TM, Danesi R, Kohn EC, Dahut WL, Kummar S, Venzon D, Liewehr D, English BC, Baum CE, et al: Hypertension and hand-foot skin reactions related to VEGFR2 genotype and improved clinical outcome following bevacizumab and sorafenib. J Exp Clin Cancer Res 29: 95, 2010.

19. Kim DH, Xu W, Kamel-Reid S, Liu X, Jung CW, Kim S and Lipton JH: Clinical relevance of vascular endothelial growth factor (VEGFA) and VEGF receptor (VEGFR2) gene polymorphism on the treatment outcome following imatinib therapy. Ann Oncol 21: 1179-1188, 2010.

20. Wang Y, Zheng Y, Zhang W, Yu H, Lou K, Zhang Y, Qin Q, Zhao B, Yang Y and Hui R: Polymorphisms of KDR gene are associated with coronary heart disease. J Am Coll Cardiol 50: 760-767, 2007.

21. Zhang W, Sun K, Zhen Y, Wang D, Wang Y, Chen J, Xu J, Hu FB and Hui R: VEGF receptor-2 variants are associated with susceptibility to stroke and recurrence. Stroke 40: 2720-2726, 2009.

22. Kariž S and Petrovič D: Minor association of kinase insert domain-containing receptor gene polymorphism (rs2071559) with myocardial infarction in Caucasians with type 2 diabetes mellitus: Case-control cross-sectional study. Clin Biochem 47: 192-196, 2014

23. Yap RW, Shidoji Y,Hon WM and Masaki M: Association and interaction between dietary pattern and VEGF receptor-2 (VEGFR2) gene polymorphisms on blood lipids in Chinese Malaysian and Japanese adults. Asia Pac J Clin Nutr 21: 302-311, 2012.

24. Sahebkar A, Morris DR, Biros E and Golledge J: Association of single nucleotide polymorphisms in the gene encoding platelet endothelial cell adhesion molecule-1 with the risk of myocardial infarction: A systematic review and meta-analysis. Thromb Res 132: 227-233, 2013

25. Listi F, Caruso C, Di Carlo D, Falcone C, Boiocchi C, Cuccia M and Candore G: Association between platelet endothelial cellular adhesion molecule-1 polymorphisms and atherosclerosis: Results of a study on patients from northern Italy. Rejuvenation Res 13: 237-241, 2010.

26. Wei YS, Lan Y, Liu YG, Meng LQ, Xu QQ and Xie HY: Platelet-endothelial cell adhesion molecule-1 gene polymorphism and its soluble level are associated with ischemic stroke. DNA Cell Biol 28: 151-158, 2009.

27. Goodman RS, Kirton CM, Oostingh GJ, Schon MP, Clark MR, Bradley JA and Taylor CJ: PECAM-1 polymorphism affects monocyte adhesion to endothelial cells. Transplantation 85 : 471-477, 2008

28. Machiela MJ and Chanock SJ: LDlink: A web-based application for exploring population-specific haplotype structure and linking correlated alleles of possible functional variants. Bioinformatics 31: 3555-3557, 2015.

29. Machiela MJ and Chanock SJ: LDassoc: An online tool for interactively exploring genome-wide association study results and prioritizing variants for functional investigation. Bioinformatics 34: 887-889, 2018.
30. Fitzpatrick M: Measuring Cell Fluorescence using ImageJ. Science Tech Blog, 2011. https://theolb.readthedocs.io/en/latest/ imaging/measuring-cell-fluorescence-using-imagej.html.

31. Cicha I, Urschel K, Daniel WG and Garlichs CD: Telmisartan prevents VCAM-1 induction and monocytic cell adhesion to endothelium exposed to non-uniform shear stress and TNF- $\alpha$. Clin Hemorheol Microcirc 48: 65-73, 2011.

32. Hopkins CR, Miller K and Beardmore JM: Receptor-mediated endocytosis of transferrin and epidermal growth factor receptors: A comparison of constitutive and ligand-induced uptake. J Cell Sci Suppl 3: 173-186, 1985.

33. Goh LK and Sorkin A: Endocytosis of receptor tyrosine kinases. Cold Spring Harb Perspect Biol 5: a017459, 2013.

34. Sorkin A and von Zastrow M: Endocytosis and signalling: Intertwining molecular networks. Nat Rev Mol Cell Biol 10: 609-622, 2009.

35. Murdaca J, Treins C, Monthouel-Kartmann MN, Pontier-Bres R, Kumar S, Van Obberghen E and Giorgetti-Peraldi S: Grb10 prevents Nedd4-mediated vascular endothelial growth factor receptor-2 degradation. J Biol Chem 279: 26754-26761, 2004.

36. Sigismund S, Confalonieri S, Ciliberto A, Polo S, Scita G and Di Fiore PP: Endocytosis and signaling: Cell logistics shape the eukaryotic cell plan. Physiol Rev 92: 273-366, 2012.

37. Gampel A, Moss L, Jones MC, Brunton V, Norman JC and Mellor H: VEGF regulates the mobilization of VEGFR2/KDR from an intracellular endothelial storage compartment. Blood 108: 2624-2631, 2006.

38. Basagiannis D and Christoforidis S: Constitutive endocytosis of VEGFR2 protects the receptor against shedding. J Biol Chem 291: 16892-16903, 2016.

39. Zhang Y, Pillai G, Gatter K, Blazquez C, Turley H, Pezzella F and Watt SM: Expression and cellular localization of vascular endothelial growth factor $\mathrm{A}$ and its receptors in acute and chronic leukemias: An immunohistochemical study. Hum Pathol 36: 797-805, 2005.

40. Blazquez C, Cook N, Micklem K, Harris AL, Gatter KC and Pezzella F: Phosphorylated KDR can be located in the nucleus of neoplastic cells. Cell Res 16: 93-98, 2006.

41. Stewart M, Turley H, Cook N, Pezzella F, Pillai G, Ogilvie D, Cartlidge S, Paterson D, Copley C, Kendrew J, et al: The angiogenic receptor KDR is widely distributed in human tissues and tumours and relocates intracellularly on phosphorylation. An immunohistochemical study. Histopathology 43: 33-39, 2003.

42. Domingues I, Rino J, Demmers JA, de Lanerolle P and Santos SC: VEGFR2 translocates to the nucleus to regulate its own transcription. PLoS One 6: e25668, 2011.

43. Conway D and Schwartz MA: Lessons from the endothelial junctional mechanosensory complex. F1000 Biol Rep 4: 1, 2012.

44. Shay-Salit A, Shushy M, Wolfovitz E, Yahav H, Breviario F, Dejana E and Resnick N: VEGF receptor 2 and the adherens junction as a mechanical transducer in vascular endothelial cells. Proc Natl Acad Sci USA 99: 9462-9467, 2002.

45. Wang Y, Chang J, Li YC, Li YS, Shyy JY and Chien S: Shear stress and VEGF activate IKK via the Flk-1/Cbl/Akt signaling pathway. Am J Physiol Heart Circ Physiol 286: H685-H692, 2004

46. Jin ZG, Ueba H, Tanimoto T, Lungu AO, Frame MD and Berk BC: Ligand-independent activation of vascular endothelial growth factor receptor 2 by fluid shear stress regulates activation of endothelial nitric oxide synthase. Circ Res 93: 354-363, 2003.

47. Li L, Pan Y, Dai L, Liu B and Zhang D: Association of genetic polymorphisms on vascular endothelial growth factor and its receptor genes with susceptibility to coronary heart disease. Med Sci Monit 22: 31-40, 2016.

48. Liu D, Song J, Ji X, Liu Z, Cong M and Hu B: Association of genetic polymorphisms on VEGFA and VEGFR2 with risk of coronary heart disease. Medicine (Baltimore) 95: e3413, 2016.

49. Medicine USNLo: [SNP Database]. https://www.ncbi.nlm.nih. gov/snp.

50. Zhang H, Zhai Q, Zhang Z, Cai B, Cai H, Zhou S, Sun L, Xie Y, Kong D, Xu Z, et al: Association of GWAS-Supported Variants rs556621 on Chromosome 6p21.1 with large artery atherosclerotic stroke in a Southern Chinese Han Population. Neuromolecular Med 19: 94-100, 2017.

This work is licensed under a Creative Commons

Attribution-NonCommercial-NoDerivatives 4.0 International (CC BY-NC-ND 4.0) License. 